\title{
Treatment of pulmonary disease caused by opportunist mycobacteria
}

During the early 1950 s it was recognised that mycobacteria other than Mycobacterium tuberculosis could cause pulmonary disease in man. ${ }^{\prime}$ Over 30 years later there is no general agreement about the treatment of patients with these mycobacterial infections. The greatest controversy surrounds the treatment of infection caused by the $\boldsymbol{M}$ avium-intracellularescrofulaceum complex (MAIS), for which various treatments have been advocated, including chemotherapy with three ${ }^{23}$ or more $e^{4-6}$ drugs or, alternatively, surgical resection of the affected lung. ${ }^{78}$ Although the treatment of infection caused by $M$ kansasii is less controversial there is no uniform approach to treatment. Disease caused by $M$ xenop $i$ has been described by some as easy to treat with chemotherapy, ${ }^{9}$ whereas others have found the response to drug treatment to be unpredictable. ${ }^{1011}$

This diversity of opinion and approach to treatment has arisen for two reasons. Firstly, there have been no large prospective studies designed to compare treatment regimens. Secondly, the failure to consider infection caused by $M$ kansasii, the MAIS complex, and other opportunist mycobacteria as entities distinct from infection caused by $M$ tuberculosis has led to inappropriate comparisons with tuberculosis. As a result principles that govern the treatment of tuberculosis, in particular the role of in vitro drug sensitivity tests, and criteria by which response to treatment is assessed have been empirically extended to disease caused by other mycobacterial species. It was realised in early reports that patients with infection caused by $M$ kansasii often remained sputum culture positive and showed persistent cavities on their chest radiographs after a few months' treatment with combinations of isoniazid, para-aminosalicyclic acid (PAS) and streptomycin. ${ }^{12-16}$ The results were poor by comparison with the prompt bacteriological and radiographic responses in patients with tuberculosis given the same treatment and raised doubts about the use of chemotherapy in opportunist mycobacterial disease. ${ }^{12-16}$ In 1963 the American Thoracic Society

Address for reprint requests: Dr J Banks, Department of Chest Medicine, Llandough Hospital, Penarth, S Glam CF6 IXX. recommended that surgical treatment for opportunist mycobacterial infection should be given to those patients who are suitable surgical candidates. ${ }^{17}$ The failure of chemotherapy was often attributed to drug resistance,,$^{12-1418}$ but the importance of prolonging the duration of chemotherapy in opportunist mycobacterial disease beyond that which would normally be required in tuberculosis was not appreciated. In several surgically treated series preoperative chemotherapy was given on average for only four to seven months, ${ }^{13}{ }^{19-22}$ some patients receiving as little as eight weeks of treatment before surgery. ${ }^{2324}$ In contrast, chemotherapy alone, with isoniazid, $p$-aminosalicyclic acid, and streptomycin for 24 months, produced successful results in $80-100 \%$ of patients with $M$ kansasii infection despite reports of in vitro resistance to these agents. ${ }^{25-28}$

\section{In vitro drug sensitivity testing in opportunist mycobac-} terial disease

Many studies show that the results of in vitro drug sensitivity tests performed against opportunist mycobacteria bear little relation to the clinical response observed when these drugs are used in treatment. ${ }^{231025-30}$ The results of treatment with agents such as cycloserine and ethionamide, which often show good in vitro action, has been disappointing ${ }^{210}$ and may reflect drug toxicity and poor compliance by patients. ${ }^{231}$ Paradoxically, successful treatment has been achieved with combinations of standard antimycobacterial agents, despite reported in vitro resistance, though the duration of treatment has had to be prolonged in these circumstances. ${ }^{23103132}$ Good in vitro sensitivity to first line agents has allowed the duration of chemotherapy to be shortened-for example, short course chemotherapy for infection caused by $M$ kansasii is possible with regimens containing rifampicin. ${ }^{33-35}$

Critical levels of in vitro resistance that have clinical importance have been defined for $M$ tuberculosi ${ }^{36}$ but not for other mycobacterial species. Nevertheless, isolates of opportunist mycobacteria are reported as "resistant" if the minimum inhibitory concentrations of drugs that suppress their growth in vitro exceed the minimum inhibitory concentrations for drug sensitive 
strains of $M$ tuberculosis. ${ }^{37}$ The comparison with $M$ tuberculosis makes the assumption that critical levels of in vitro resistance that predict treatment failure in $M$ tuberculosis infection are the same for all mycobacteria, irrespective of species. Clearly this is not so. Isolates of mycobacteria belonging to the MAIS complex or of $M$ xenopi or $M$ malmoense should not therefore be classified as resistant until in vitro criteria that correlate with the clinical results of treatment of these infections have been established.

Drug resistance cannot be defined simply by relating in vitro minimum inhibitory concentrations to serum drug concentrations as the latter do not necessarily reflect drug concentrations achieved within tissues and macrophages. For example, concentrations of ethambutol in both normal and caseous lung tissue are several times higher than the concentrations in plas$\mathrm{ma}^{38}$ and even higher drug concentrations are achieved within alveolar macrophages. ${ }^{39}{ }^{40}$ In addition, concentrations of ethambutol needed to kill phagocytosed bacilli are lower than the bactericidal concentrations required in culture medium. ${ }^{41}$ Such factors may account for the effectiveness of some drugs in treatment despite their poor in vitro action.

\section{Recommendations for treatment}

Pulmonary disease most often results from infection with $M$ kansasii, the MAIS complex, $M$ xenopi, or $M$ malmoense.

M KANSASII

Infection with $M$ kansasii should be treated with regimens that include both rifampicin and ethambutol. The combination of rifampicin and ethambutol alone produced successful results in one series. ${ }^{34}$ The preliminary results of a prospective multicentre study conducted in the United Kingdom by the British Thoracic Society suggests that nine months' treatment with regimens that include both rifampicin and ethambutol will be adequate. ${ }^{35}$ Of 75 patients who had completed treatment by March 1986, 14 had received rifampicin combined with ethambutol and 61 had been given rifampicin and ethambutol combined with one or more additional drugs, usually isoniazid. These additional drugs were given for less than three months at the start of treatment in most patients. One failure of treatment resulted from non-compliance with drug treatment and two deaths occurred from unrelated pneumonia. Successful results were obtained in the remaining patients, $100 \%$ sputum conversion to culture negative being achieved within nine months of the start of treatment. Three patients $(4 \%)$ subsequently relapsed, though relapse in one was associated with the development of laryngeal carcinoma.
MAIS COMPLEX

There is no consensus about the best treatment for $\vec{\Rightarrow}$ pulmonary infection caused by the MAIS complex. $\frac{3}{7}$ Surgical resection of affected lung is advocated by some, ${ }^{78}$ and others have recommended chemotherapy $\frac{\bar{\sigma}}{\bar{c}}$ with standard antimycobacterial drugs. ${ }^{23}$ The results $\vec{\Phi}$ following surgical treatment have undoubtedly been $\frac{2}{0}$ good, conversion to sputum culture negative being $\mathrm{c}$ achieved postoperatively in $93-100 \%$ of cases in some $\vec{\circ}$ series, and relapses occurring in only $5 \%$ of patients $\overrightarrow{-}$ during prolonged follow up. ${ }^{78}$ These results are more $\vec{\sigma}^{\circ}$ impressive than those obtained with chemotherapy alone, ${ }^{162-44}$ but comparisons of this nature do not $\times$ compare like with like. Patients included in surgically treated series are often selected in so far as they have os less extensive disease and have sufficiently good car- $\vec{t}$ diopulmonary reserve to withstand thoracotomy and pulmonary resection. ${ }^{78}$ Even in centres where surgery $\frac{}{5}$ is strongly advocated they have comprised no more $\vec{c}$ than $30-40 \%$ of all patients treated. ${ }^{8}$ In addition, many have received adjunctive chemotherapy, which ${ }^{\Phi}$ in some cases has been continued for two or three $\vec{\varphi}$ years. $^{78}$ In contrast, patients treated with chemotherapy alone have often had other serious pulmonary 0 conditions, which in some cases were considered to be more important prognostically than the mycobacterial infection itself. ${ }^{45}$ Interestingly, $94 \%$ of patients in one series who had no coexistent lung disorder, and who $\frac{\circ}{\mathbb{D}}$ were not breathless on admission, converted to $\stackrel{2}{\Rightarrow}$ sputum culture negative and showed radiographic improvement in response to chemotherapy alone. ${ }^{3}$ The median follow up was 22 months, during which time $6 \%$ of patients relapsed. These initial results are as good as those obtained with surgery and, although follow up was relatively short, are far better than the results reported in many other medically treated series. Surgical treatment, even in selected patients, has not 3 . always been successful. In one series $33 \%$ of patients ultimately relapsed after having surgery ${ }^{45}$; in another $\frac{\circ}{3}$ series complications, including bronchopleural fistula, $O$ developed in $24 \%$ of patients and there was a $7 \%$ ? postoperative mortality.?

Medical treatment is the only therapeutic option available for many patients. Pessimistic reports on the $N$ results of chemotherapy have often failed to indicate $N$ the duration of treatment given before it was con- $N$ cluded to be unsuccessful. ${ }^{162842-44}$ Treatment with $\omega$ rifampicin and isoniazid combined with either ethambutol or streptomycin was successful in $84 \%$ of cases in one series when treatment was prolonged. ${ }^{2}$ Two years of treatment appeared to offer the best chance of $\stackrel{+}{+}$ success. ${ }^{2}$ Unfortunately, $16 \%$ of patients failed to 0 respond to chemotherapy and $13 \%$ relapsed within $\underset{\mathbb{D}}{ }$ one year of completing treatment. ${ }^{2}$ Treatment with five $\frac{?}{8}$ or six drug regimens has been advocated, particularly $\varrho$ for progressive disease, ${ }^{4-6}$ but there have been no

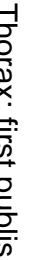


comparative studies showing that such multiple regimens are more effective than those comprising fewer drugs. The British Thoracic Society is at present conducting a prospective study in which 24 months' treatment with rifampicin, ethambutol, and isoniazid is being compared with 24 months of rifampicin and ethambutol; patients treated with other drugs or surgery are also being followed up.

\section{XENOPI}

Pulmonary infection with $M$ xenopi has been classified as easy to treat,' but reports describing successful treatment have frequently been based on small series or case reports of individual patients with short follow up. ${ }^{46-50}$ The results from larger series indicate that the response to chemotherapy in this condition is unpredictable. ${ }^{1011}$ Most patients improve while receiving treatment and convert to sputum culture negative. ${ }^{10}$ Some are cured, but $26 \%$ of patients in one series relapsed and $10 \%$ developed progressive disease while receiving treatment with drugs that showed good in vitro activity. ${ }^{10}$ The best results were obtained with regimens that included rifampicin, ethambutol, and isoniazid. ${ }^{10}$ Surgery has been effective in controlling the disease in a small number of patients ${ }^{51}$; it should be considered for patients who either relapse or fail to respond to initial chemotherapy.

\section{MALMOENSE}

There have been few reports describing the response to treatment of pulmonary infection caused by $M$ malmoense. Successful results have been obtained with a combination of rifampicin, ethambutol, and isoniazid given for 18-24 months but follow up was relatively short. ${ }^{31}$ Ethambutol seems to be crucially important in this regimen as its withdrawal was followed by clinical deterioration in several patients. ${ }^{31}$

\section{Drug synergism}

Synergism between standard antimycobacterial drugs may account for their effectiveness in treatment. In vitro studies have shown that drugs in combination are more effective than single agents in suppressing the growth of $M$ kansasii, ${ }^{52}{ }^{53}$ MAIS,,${ }^{5457} M$ xenopi ${ }^{58}$ and $M$ malmoense. ${ }^{58}$ Rifampicin combined with ethambutol was particularly effective against strains of $M$ malmoense and $M$ xenopi (figure), and inhibited one third

\section{$M$ malmoense}
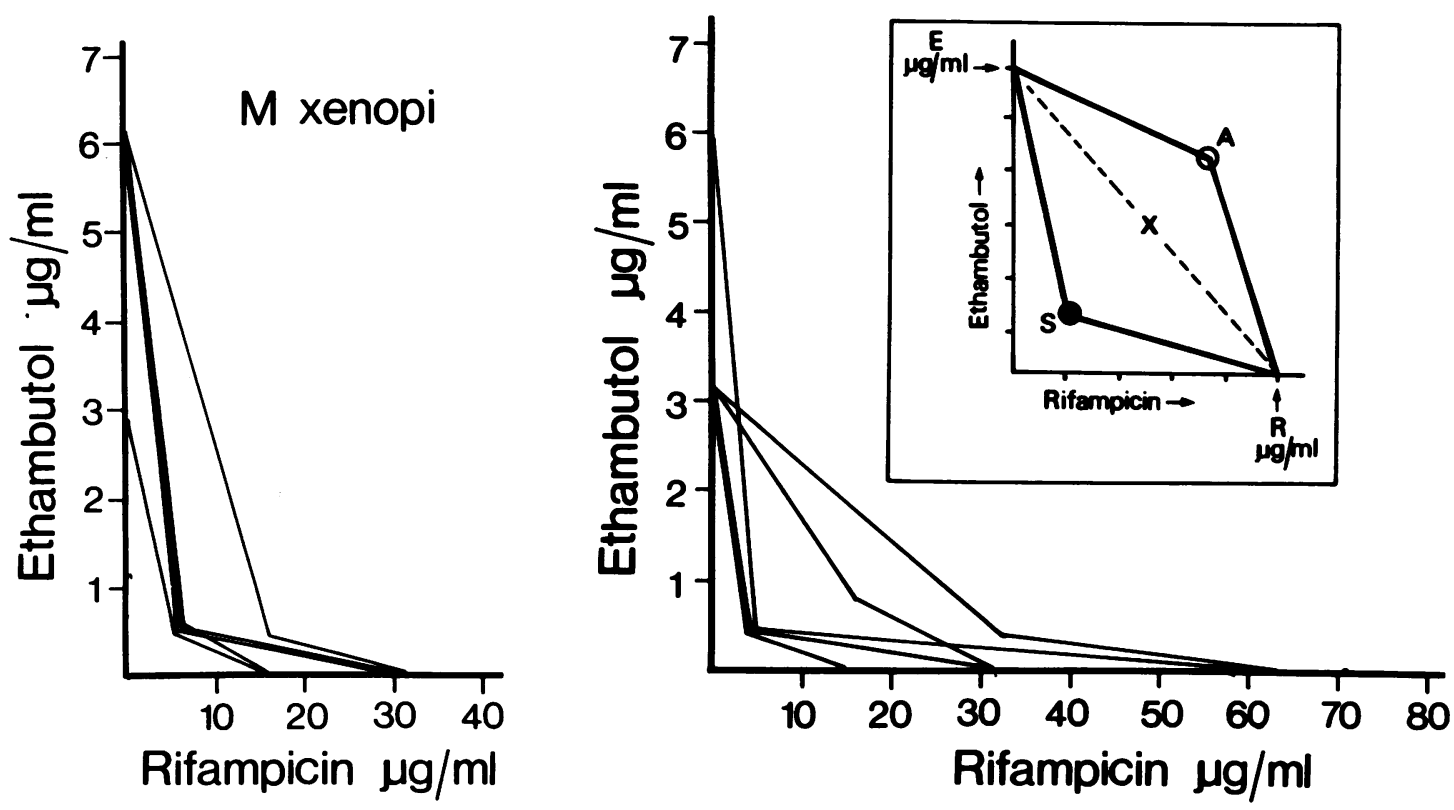

Isobolograms for five strains of Mycobacterium malmoense and five strains of $M$ xenopi tested against ethambutol combined with rifampicin. A line or isobol is drawn for each strain, which joins the minimum effective concentration of ethambutol when used alone (on the ordinate) with the minimum effective concentration of rifampicin when used alone (on the abscissa) through the point which represents their minimum effective concentrations when combined. The inset shows three theoretical isobols. Drug combinations that are synergistic produce concave isobols (ESR), antagonistic combinations produce convex isobols $(E A R)$, and additive combinations produce straight lines (EXR). Each strain of $M$ malmoense and $M$ xenopi produced a concave isobol consistent with a synergistic effect between rifampicin and ethambutol. Reproduced from Banks et al. ${ }^{68}$ 
of strains of the MAIS complex that had shown poor in vitro susceptibility to the single agents. ${ }^{58}$ Similar results have been obtained by workers using different techniques for culture and sensitivity testing. ${ }^{59}$ A mechanism for synergy between these two agents has been proposed. ${ }^{60}$ Rifampicin acts against mycobacteria by inhibiting bacterial DNA dependent RNA polymerase, thus blocking transcription. ${ }^{6162}$ Rifampicin resistant strains of $M$ tuberculosis have a resistant polymerase, which is not inhibited by the drug. ${ }^{6364}$ In contrast, rifampicin resistance among opportunist mycobacteria seems to be due to a failure of the drug to penetrate the bacterial cell wall. ${ }^{65}$ The RNA polymerase of rifampicin resistant strains belonging to the MAIS complex is highly sensitive to rifampicin. ${ }^{65}$ Ethambutol, even in low concentrations, induces morphological changes in the bacterial cell wall in vitro, ${ }^{66}$ probably by interfering with mycolic acid ${ }^{6768}$ and phospholipid synthesis. ${ }^{69}$ This action on the cell wall might facilitate access of rifampicin into the cell, thus exposing its rifampicin sensitive polymerase. A similar action in vivo might explain the effectiveness of the combination of rifampicin and ethambutol in treatment.

\section{Opportunist mycobacterial disease in patients} with human immunodeficiency virus infection

Opportunist mycobacterial disease in patients with HIV infection differs substantially in its clinical presentation and response to treatment from the localised pulmonary infection seen in patients who do not have HIV infection. Disseminated disease is the most common manifestation and patients frequently present with fever, weight loss, and malaise. ${ }^{70-72}$ Gastrointestinal symptoms may predominate. ${ }^{73}$ Fever, enlarged lymph glands, hepatosplenomegaly, and skin lesions are the most common findings. Although physical signs in the chest are less common, the chest radiograph is usually abnormal and may show a wide range of abnormalities, including mediastinal adenopathy, pulmonary nodules, and patchy alveolar infiltrates. ${ }^{74}$ The response to chemotherapy has been poor, though the clinical picture is often obscured by other opportunist infections. ${ }^{713}$ Multiple drug regimens that include rifampicin, ansamycin, ethambutol, clofazamine, ethionamide, and streptomycin have been advocated ${ }^{75}$ but, despite good in vitro action shown by several of these drugs, the clinical response has been disappointing. ${ }^{70} 72$

\section{Summary}

Opportunist mycobacterial infections localised to the chest may be treated with combinations of standard antimycobacterial drugs. The combination of rifampicin and ethambutol seems to be particularly effec- tive, both in vivo and in vitro. In vitro sensitivity testing with single drugs may have a role in the future when the levels of in vitro resistance compatible with the clinical response to treatment are eventually established. Sensitivity testing against drugs in combination may prove useful for modifying treatment regimens in those patients who either fail to respond to initial chemotherapy or relapse. Further evidence on this will, it is hoped, emerge from the prospective studies currently in progress.

I am grateful to Drs I A Campbell and A P Smith, consultant chest physicians, Llandough Hospital, and Dr P A Jenkins, director of the Mycobacterium Reference Laboratory (Public Health Laboratory os Service), Cardiff, for their valuable comments, and to Heather Thomas for typing the manuscript. JOHN BANKS Department of Chest Medicine $\vec{c}$ Llandough Hospital Cardiff

\section{References}

1 Runyon EH. Veterans Administration-National Tuberculosis Association Co-operative Study of Mycobacteria [letter]. Am Rev Tuberc 1955;72:866-9.

2 Hunter AM, Campbell IA, Jenkins PA, Smith AP. Treatment of pulmonary infection caused by mycobacteria of the Mycobacterium avium-intracellulare complex. Thorax 1981;36:326-9.

3 Engbaek HC, Vergmann B, Bentzon MW. A prospective study of lung disease caused by Mycobacterium avium/ Mycobacterium intracellulare. Eur J Respir Dis 1984; 65:411-8.

4 Yaeger H Jr, Raleigh JW. Pulmonary disease due to $\stackrel{0}{x}$ Mycobacterium intracellulare. Am Rev Respir Dis 음 1973;108:547-52.

5 Lester TW. Drug-resistant and atypical mycobacterial $\delta$ disease. Bacteriology and treatment. Arch Intern Med 1979;139:1399-401.

6 Lester W, Moulding T, Fraser RI, McClatchy K, Fischer 을 DA. Quintuple drug regimens in the treatment of $\frac{D}{8}$ Battey-type infections In: Transactions of the 28th Pulmonary Disease Research Conference. Veterans N Association-Armed Forces, 1969:83.

7 Corpe RF. Surgical management of pulmonary disease $\mathrm{O}$ due to Mycobacterium avium-intracellulare. Rev Infect Dis 1981;3:1064-7.

8 Moran JF, Alexander LG, Staub EW, Young WG Jr, Sealy WC. Long-term results of pulmonary resection for atypical mycobacterial disease. Ann Thorac Surg $\mathbb{\Phi}$ 1983;35:597-604.

9 Bailey WC. Treatment of atypical mycobacterial disease. Chest 1983;84:625-8.

10 Banks J, Hunter AM, Campbell IA, Jenkins PA, Smith AP. Pulmonary infection with Mycobacterium xenopi: $\mathbb{D}$ a review of treatment and response. Thorax 1984; 39:376-82. 
11 Smith MJ, Citron KM. Clinical review of pulmonary disease caused by Mycobacterium xenopi. Thorax 1983;38:373-7.

12 Lester W Jr, Botkin J, Colton R. An analysis of forty-nine cases of pulmonary disease caused by photochromogenic mycobacteria. In: Transactions of the 17th Conference on the Chemotherapy of Tuberculosis. Veterans Association-Armed Forces, 1958:289-97.

13 Jenkins DE, Bahar D, Chofnas I, Foster R, Barkley HT. The clinical problem of infection with atypical acid-fast bacilli. Trans Am Clin Climat Assoc 1959;71:21-33.

14 Christianson LC, Dewlett JH. Pulmonary disease in adults associated with unclassified mycobacteria. Am J Med 1960;29:980-91.

15 Goldman KP. Treatment of unclassified mycobacterial infection of the lungs. Thorax 1968;23:94-9.

16 Phillips S, Larkin JC Jr. Atypical pulmonary tuberculosis caused by unclassified mycobacteria. Ann Intern Med 1964;60:401-8.

17 Corpe RF, Runyon EH, Lester W. Status of disease due to unclassified mycobacteria. A statement of the subcommittee on unclassified mycobacteria of the committee on therapy. Am Rev Respir Dis 1963;87:459-61.

18 Wood LE, Buhler VB, Pollak A. Human infection with the "Yellow" acid fast bacillus. Am Rev Tuberc 1956; 73:917-29.

19 Elston HR, Parrillo OJ, Meiberger M, Kleitsch WP. Pulmonary mycobacteriosis. Arch Intern Med 1963; 113:365-72.

20 Law SW. Surgical treatment of atypical mycobacterial disease. Dis Chest 1965;47:296-303.

21 Shah HH, Holland RH, Meador RS, Webb WR. The surgical variations of pulmonary infection caused by different species of mycobacteria. Ann Thorac Surg 1969;7:145-9.

22 Johanson WG Jr, Nicholson DP. Pulmonary disease due to Mycobacterium kansasii. An analysis of some factors affecting prognosis. Am Rev Respir Dis 1969;99:73-85.

23 Harrison RW, Reimann AF, Long ET, Lester W Jr, Adams WE. Adverse surgical experience in the treatment of pulmonary disease caused by atypical acid-fast bacilli. J Thorac Cardiovasc Surg 1959;38:481-500.

24 Zvetina JR, Neville WE, Maben HC Langston HT, Correll NO Jr. Surgical treatment of pulmonary disease due to Mycobacterium kansasii. Ann Thorac Surg 1971;11:551-6.

25 Pfuetze KH, Vo LV, Reimann AF, Berg GS, Lester W. Photochromogenic mycobacterial pulmonary disease. Am Rev Respir Dis 1965;92:470-5.

26 Pfuetze KM, Nuchprayoon CV, Berg GS, Pamintuan R. Present status of open negative cavities due to photochromogenic mycobacteria among co-operative patients. Am Rev Respir Dis 1966;94:467.

27 Lester W. Unclassified mycobacterial disease. Am Rev Med 1966;17:351-60.

28 Bates JH. A study of pulmonary disease associated with mycobacteria other than Mycobacterium tuberculosis. Clinical characteristics: XX. A report of the Veterans Administration-Armed Forces study on the chemotherapy of tuberculosis. Am Rev Respir Dis 1967; 96:1151-7.

29 Fischer DA, Lester W, Schaefer WB. Infection with atypical mycobacteria. Am Rev Respir Dis 1968;98: 29-34.

30 Rauscher CR, Kerby G, Ruth WE. A ten year clinical experience with Mycobacterium kansasii. Chest 1974; 66:17-9.

31 Banks J, Jenkins PA, Smith AP. Pulmonary infection with Mycobacterium malmoense-a review of treatment and response. Tubercle 1985;66:197-203.

32 France AJ, McLeod DT, Calder MA, Seaton A. Mycobacterium malmoense infections in Scotland: an increasing problem. Thorax 1987;42:593-5.

33 Ahn CH, Lowell JR, Anh SS, Ahn SI, Hurst GA. Short course chemotherapy for pulmonary disease caused by Mycobacterium kansasii. Am Rev Respir Dis 1983;128:1048-50.

34 Banks J, Hunter AM, Campbell IA, Jenkins PA, Smith AP. Pulmonary infection with Mycobacterium kansasii in Wales, 1970-9: review of treatment and response. Thorax 1983;38:271-4.

35 Campbell IA, on behalf of BTS Research Committee. BTS study of 9 months' treatment with rifampicin and ethambutol in Mycobacterium kansasii pulmonary infecton [abstract]. Thorax 1986;41:709.

36 Selkon JB, Mitchison DA. A concept of drug resistance. In: Transactions of the 17th Conference on the Chemotherapy of Tuberculosis. Veterans Association-Armed Forces, 1958:258-64.

37 Marks J. A system for the examination of tubercle bacilli and other mycobacteria. Tubercle 1976;57:207-25.

38 Djurovic V, DeCroix G, Daumet P. L'ethambutol chez l'homme. Etude comparative des taux seriques erythrocytaires et pulmonaires. Nouv Presse Med 1973; ii: $2815-6$.

39 Johnson JD, Hand WL, Francis JB, King-Thompson N, Corwin RW. Antibiotic uptake by alveolar macrophages. J Lab Clin Med 1980;95:429-39.

40 Liss RH. Antimycobacterial activity of ethambutol in human pulmonary mononuclear phagocytes. Prax Klin Pneumol 1983;37:485-6.

41 Crowle AJ, Sbarbaro J, Judson FN, May MH. The effect of ethambutol on tubercle bacilli within cultured human macrophages. Am Rev Respir Dis 1985; 132:742-5.

42 Lewis AG Jr, Dunbar FP, Lasche EM, et al. Chronic pulmonary disease due to atypical mycobacterial infections. Am Rev Respir Dis 1959;80:188-99.

43 Carruthers KJM, Edwards FGB. Atypical mycobacteria in Western Australia. Am Rev Respir Dis 1965;91: 887-95.

44 Corpe RF, Liang JL, Sanchez ES. Early and late results in persons with atypical group III tuberculosis. Am Rev Respir Dis 1975;111:915.

45 Rosenzweig DY. Pulmonary mycobacterial infections due to Mycobacterium intracellulare-avium complex. Chest 1979;75:115-9.

46 Elston HR, Duffy JP. Mycobacterium xenopi and mycobacteriosis. A clinical and bacteriological report. Am Rev Respir Dis 1973;108:944-9.

47 Engbaek HC, Vergmann B, Baess I, Will DW. M xenopi. A bacteriological study of $M$ xenopi including case reports of Danish patients. Acta Pathol Microbiol Scand 1967;69:576-94. 
48 Tellis CJ, Beechler CR, Ohashi DK, Fuller SA. Pulmonary disease caused by Mycobacterium xenopi. Two case reports. Am Rev Respir Dis 1977;116:779-83.

49 Koizumi JH, Sommers HM. Mycobacterium xenopi and pulmonary disease. Am J Clin Pathol 1980;73:826-30.

50 Bogaerts Y, Elinck W, Van Renterghem D, Pauwels R, Van Der Straeten M. Pulmonary disease due to Mycobacterium xenopi. Report of two cases. Eur J Respir Dis 1982;63:298-304.

51 Thibier R, Vivien JN, Lepeuple A. Sept cas de pleuropneumopathie "Mycobacterium xenopi." Rev Tuberc Pneumol 1970;34:623-5.

52 Rynearson TK, Shronts JS, Wolinsky E. Rifampin: In vitro effect on atypical mycobacteria. Am Rev Respir Dis 1971;104:272-4.

53 Tsang AY, Bentz RR, Schork MA, Sodeman TM. Combined vs single drug studies of susceptibilities of Mycobacterium kansasii to isoniazid, streptomycin and ethambutol. Am J Clin Pathol 1978;138:816-20.

54 Zimmer BL, DeYoung DR, Roberts GD. In vitro synergistic activity of ethambutol, isoniazid, kanamycin, rifampin, and streptomycin against $M y c o b a c$ terium avium-intracellulare complex. Antimicrob Agents Chemother 1982;22:148-50.

55 Nash DR, Steingrube VA. Selecting drug combinations for treatment of drug-resistant mycobacterial diseases. J Clin Pharmacol 1982;22:297-300.

56 Heifets LB. Synergistic effect of rifampin, streptomycin, ethionamide, and ethambutol on Mycobacterium intracellulare. Am Rev Respir Dis 1982;125:43-8.

57 Kuze F. Experimental chemotherapy in chronic Mycobacterium avium-intracellulare infection of mice. Am Rev Respir Dis 1984;129:453-9.

58 Banks J, Jenkins PA. Combined versus single antituberculosis drugs on the in vitro sensitivity patterns of nontuberculous mycobacteria. Thorax 1987;42:838-42.

59 Hoffner SE, Svenson SB, Kallenium G. Synergistic effects of antimycobacterial drug combinations on $\mathrm{Myco-}$ bacterium avium complex determined radiometrically in liquid medium. Eur J Clin Microbiol 1987;6:530-5.

60 Banks J. Treatment of pulmonary disease caused by nontuberculous mycobacteria. MD thesis, University of Manchester, 1988.

61 Sippel A, Hartmann G. Mode of action of rifampicin on the RNA polymerase reaction. Biochim Biophys Acta 1968;157:218-9.

62 Lill VR, Santo A, Sippel A, Hartmann G. Inhibitors of the RNA polymerase reaction. Colloq Ges Biol Chem
1970;20:48-59.

63 Tsukamura $M$. The pattern of resistance development to rifampin in Mycobacterium tuberculosis. Tubercle 1972;53:111-7.

64 Wehrli W, Knusel F, Schmid K, Staehelin M. Interaction of rifamycin with bacterial RNA polymerase. Proc Natl Acad Sci USA 1968;61:667-73.

65 Hui J, Gordon N, Kajioka R. Permeability barrier to rifampicin in mycobacteria. Antimicrob Agents Chemother 1977;11:773-9.

66 Kilburn JO, Greenberg J. Effect of ethambutol on the viable cell count in Mycobacterium smegmatis. Antimicrob Agents Chemother 1977;11:534-40.

67 Takayama K, Armstrong EL, Kunugi KA, Kilburn KO. Inhibition by ethambutol of mycolic acid transfer into the cell wall of Mycobacterium smegmatis. Antimicrob Agents Chemother 1979;16:240-2.

68 Kilburn JO, Takayama K. Effects of ethambutol on accumulation and secretion of trehalose mycolates and free mycolic acid in Mycobacterium smegmatis. Antimicrob Agents Chemother 1981;20:401-4.

69 Kilburn JO, Takayama K, Armstrong EL, Greenberg J. Effects of ethambutol on phospholipid metabolism in Mycobacterium smegmatis. Antimicrob Agent Chemother 1981;19:346-8.

70 Wallace JM, Hannah JB. Mycobacterium avium complex infection in patients with the acquired immunodeficiency syndrome. A clinicopathologic study. Chest 1988;93:926-32.

71 Greene JB, Siou GS, Lewin S, et al. Mycobacterium avium-intracellulare: a cause of disseminated lifethreatening infection in homosexuals and drug abusers. Ann Intern Med 1982;97:539-46.

72 Hawkins CC, Gold JW, Whimbey E, et al. Myobacterium avium complex infections in patients with the acquired immunodeficiency syndrome. Ann Intern Med 1986;105:184-8.

73 Zakowski P, Fligiel S, Berlin GW, Johnson BL Jr. Disseminated Mycobacterium avium-intracellulare infection in homosexual men dying of acquired immunodeficiency. JAMA 1982;248:2980-2.

74 Marinelli DL, Albelda SM, Williams TM, Kern JA, Iozzo RV, Miller WT. Nontuberculous mycobacterial infection in AIDS: clinical, pathologic, and radiographic features. Radiology 1986;160:77-82.

75 Iseman MD, Corpe RF, O'Brien RJ, Rosenzweig DY, Wolinsky E. Disease due to Mycobacterium aviumintracellulare. Chest 1985;87:139-49. 